\title{
In vitro release kinetics study of Esomeprazole Magnesium Trihydrate tablet available in Bangladesh and comparison with the originator brand (Nexium $\left.{ }^{\circledR}\right)$
}

\author{
*Shimul Halder1, Madhabi Lata Shuma², Abul Kalam Lutful Kabir' ${ }^{1}$, Abu Shara Shamsur Rouf ${ }^{1}$ \\ ${ }^{1}$ Department of Pharmaceutical Technology, University of Dhaka, Dhaka-1000, Bangladesh. \\ ${ }^{2}$ Department of Pharmacy, Stamford University Bangladesh, 51 Siddeswari Road, Dhaka-1217, Bangladesh.
}

Original Research Article

\begin{abstract}
The main aim of present investigation was to study the dissolution pattern of most commercially available formulations of Esomeprazole in Bangladesh. Commercially available ten national brands and originator brand of esomeprazole magnesium trihydrate tablets were studied in simulated gastric medium ( $\mathrm{pH}$ 1.2) for first 15 minutes and simulated intestinal medium ( $\mathrm{pH}$ 6.8) for next 30 minutes time period using USP reference dissolution apparatus (Type II). No brands met the dissolution pattern like the originator brand (E1). But three brands (E3, E6 and E7) were found to be very close to it in terms of dissolution pattern. One brand E11 was found to be sub-standard compared to originator one. Drug release profiles were analyzed for zero order, first order and Higuchi equation to reveal the release kinetics perspective of Esomeprazole magnesium trihydrate enteric coated tablets. It was found that first order kinetics was predominant for E1 (Originator Brand). Zero order and Higuchi release kinetics was predominant release mechanism than first order release kinetics for E2, E4 and E11. First order release kinetics was predominant for rest of the brands (E3, E5, E6, E7, E8, E9 and E10). It was found that drug release of those brands followed moderately diffusion method and concentration dependant from the dosage form. Among all of these locally manufactured Esomeprazole brands E3, E6 and E7 showed compatible dissolution pattern and release kinetics compared with the originator brand.
\end{abstract}

Key words: In vitro dissolution, Market preparations, Kinetics study, Esomeprazole, National brand, Originator brand.

\section{INTRODUCTION}

Esomeprazole, the S-isomer of omeprazole, irreversibly inhibits the gastric parietal $\mathrm{H}+/ \mathrm{K}$ ATPase enzyme involved in the production of hydrochloric acid in the stomach. It acts as proton pump inhibitor, used to treat gastroesophageal reflux disease (GERD), erosive esophagitis, and gastric ulcer etc. (Martindale, 2005). The process of in vitro dissolution played a vital role in liberating the drug from the tablet matrix

*Corresponding Author
Shimul Halder
Lecturer
Department of Pharmaceutical Technology
University of Dhaka
Dhaka-1000, Bangladesh
E-mail: sk_halder_85@yahoo.com
Contact No.: +880 1716599577

and marking whether it is available for subsequent gastrointestinal absorption. The in vitro dissolution of the drug from the tablet matrix depends on many factors, which includes not only the physiochemical properties of drug, but also the nature of formulation and the process of manufacturing (Augsburger et al., 1983). Hence in vitro dissolution analysis of pharmaceutical dosage form has emerged a very important parameter that ensured product quality as well as for differentiating among formulations of the same therapeutic agent (Ayres et al., 1984). For $\mathrm{pH}$ dependent tablets the role of in vitro dissolution becomes still more crucial as an additional coating step involved in the manufacturing process (Lordi, 1992). In vitro dissolution study is an important tool in the evaluation of the best formulation and also in the understanding of 
possible risks related to specific gastrointestinal environment, dose dumping, food effects on bioavailability and interaction with other drugs (Sungthongjeen et al., 1999). Today dissolution studies are the most frequently used tools in the development, characterization and utilization proce-sses of any formulation (Longer et al., 1990).

In Bangladesh there are a number of pharmaceutical companies manufacturing and marketing esomeprazole in tablet dosage form. Besides the national brands, there are few international brands also available in drug stores. This study deals with the comparative in vitro dissolution or in vitro bioavailability characteristics of most commonly available national and originator brand of esomeprazole in Bangladesh.

\section{MATERIALS AND METHODS}

Standard Active Drug: Esomeprazole magnesium trihydrate (Beximco Pharmaceuticals Ltd., Bangladesh). Nexium (Originator Brand), manufactured by AstraZeneca, USA and other locally manufactured drugs were purchased from local drug stores. Solvents and reagents: Hydrochloric acid (Merck, Germany); Orthophosphoric acid (Merck, Germany); Sodium hydroxide (Merck, Germany) Equipments: UV Spectrophometer (Shimadzu, Japan); Digital pH meter (Hach Company, USA); Electronic hardness tester (Ereweka, Germany); Tablet dissolution tester (Electrolab, India); Sartorius electronic balance.

\section{Dosages forms}

Ten national brands with originator brand of marketed (production date not more than four months ago from the time of purchase) esomeprazole tablets of the test drug were collected from various stores. The samples were properly checked for their manufacturing license number, batch number, and date of manufacture and expiry dates before purchasing. These were randomly coded (E1) for originator brand and (E2, E3, E4, E5, E6, E7, E8, E9, E10 and E11) for national brands The labeled active ingredient was esomeprazole $20 \mathrm{mg}$ and packaged in strip or in blister packing. The strip or blister packs stored at $25 \pm 2^{\circ} \mathrm{C}$ for four weeks before the dissolution study in order to evaluate any change in organoleptic properties.

\section{In vitro dissolution study}

These studies were conducted at $37 \pm 0.5^{\circ} \mathrm{C}$ on an USP specification dissolution rate test type II apparatus (Paddle apparatus) with six section assembly according to the USP XXIII procedure with minor modification (USP XXII and NF XVII, 1995). For in vitro dissolution studies, simulated gastric medium ( $\mathrm{pH} 1.2)$ and simulated intestinal medium $(\mathrm{pH}$ 6.8) were used as dissolution media.

\section{Preparation of simulated gastric medium $(0.1 \mathrm{~N}$ $\mathrm{HCl} \mathbf{~ p H ~ 1 . 2 ) ~}$}

For $0.1 \mathrm{~N} \mathrm{HCl}, 9.61 \mathrm{ml}$ of hydrochloric acid $(40 \%$ $\mathrm{v} / \mathrm{v}$ ) was diluted with sufficient distilled water to produce $1000 \mathrm{ml}$.

\section{Acid stage}

$900 \mathrm{ml}$ of $0.1 \mathrm{NHCl}$ was placed in each vessel and the apparatus was assembled. Six tablets from each formulation were weighed and placed in the baskets. The operation in the acid stage was carried out for 15 minutes. After 15 minutes, $10 \mathrm{ml}$ of sample solution was withdrawn and filtered. The released drug was assayed by using UV spectrophotometer at $305 \mathrm{~nm}$.

\section{Buffer stage}

After 15 minutes operation in the acid stage, 20 $\mathrm{ml} \mathrm{NaOH}(25 \%)$ was added to the previous fluid. The $\mathrm{pH}(6.8 \pm 0.05)$ was adjusted with addition of $1.2 \mathrm{ml} \mathrm{O}$-phosphoric acid. The operation was continued for 30 minutes. At every 15 minutes interval, sample $(10 \mathrm{ml})$ of the solution was withdrawn from the dissolution medium and immediately compensated with equal volumes of fresh dissolution medium. The withdrawn samples $(10 \mathrm{ml})$ were then filtered and diluted, analyzed at $305 \mathrm{~nm}$ for esomeprazole by UV spectrophotometer. The amounts of drug present in the samples were calculated from calibration curves constructed from the standard solution of USP reference standard test drug. 


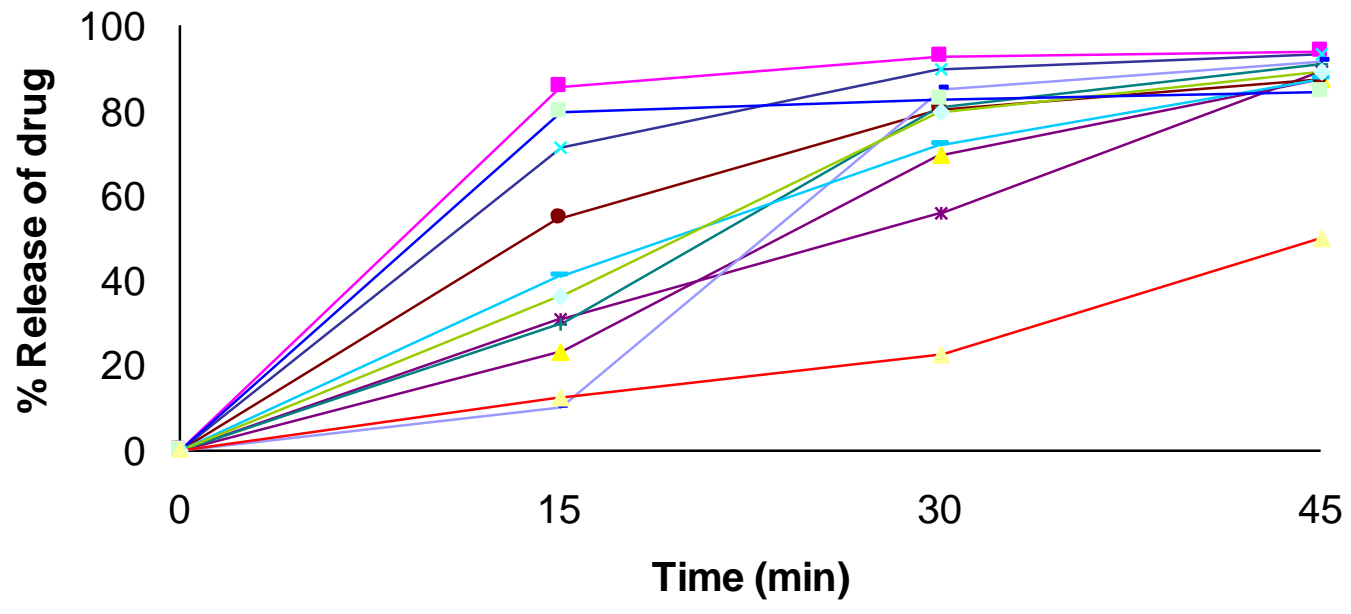

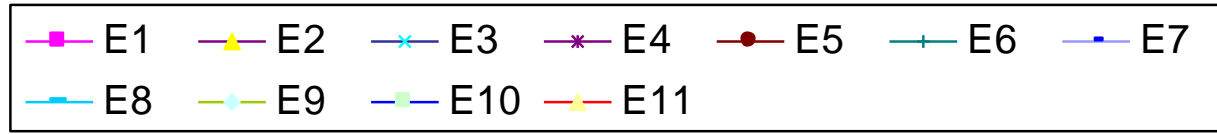

Figure 1. Zero order release profiles of different brands of Esomeprazole.

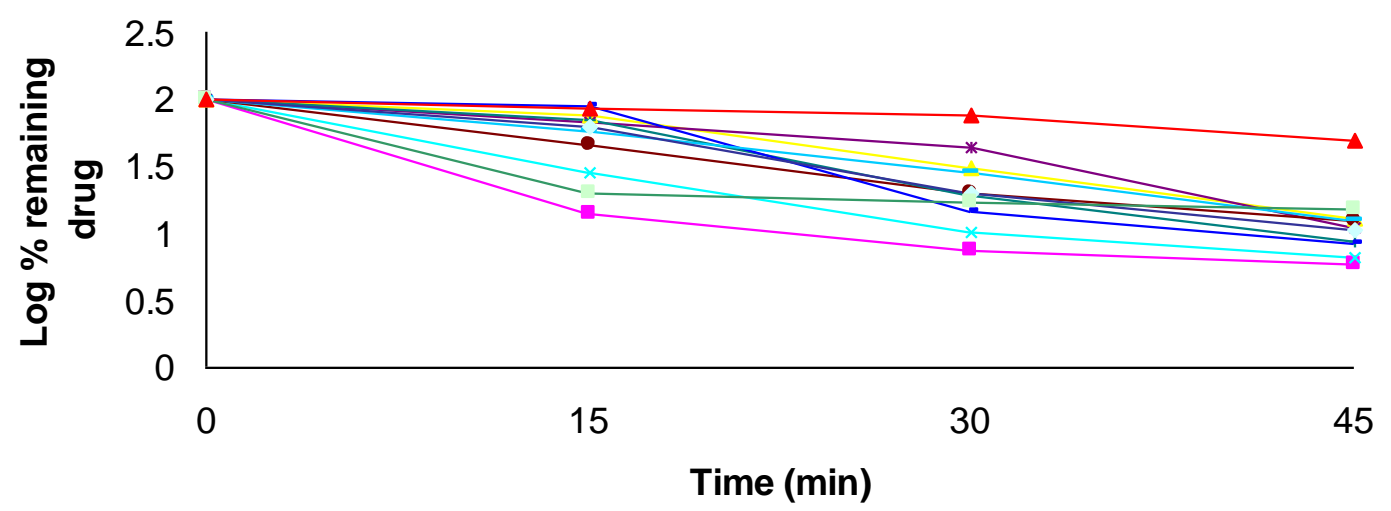

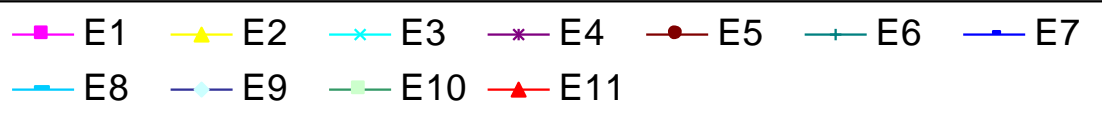

Figure 2. First order plots of different brands of Esomeprazole.

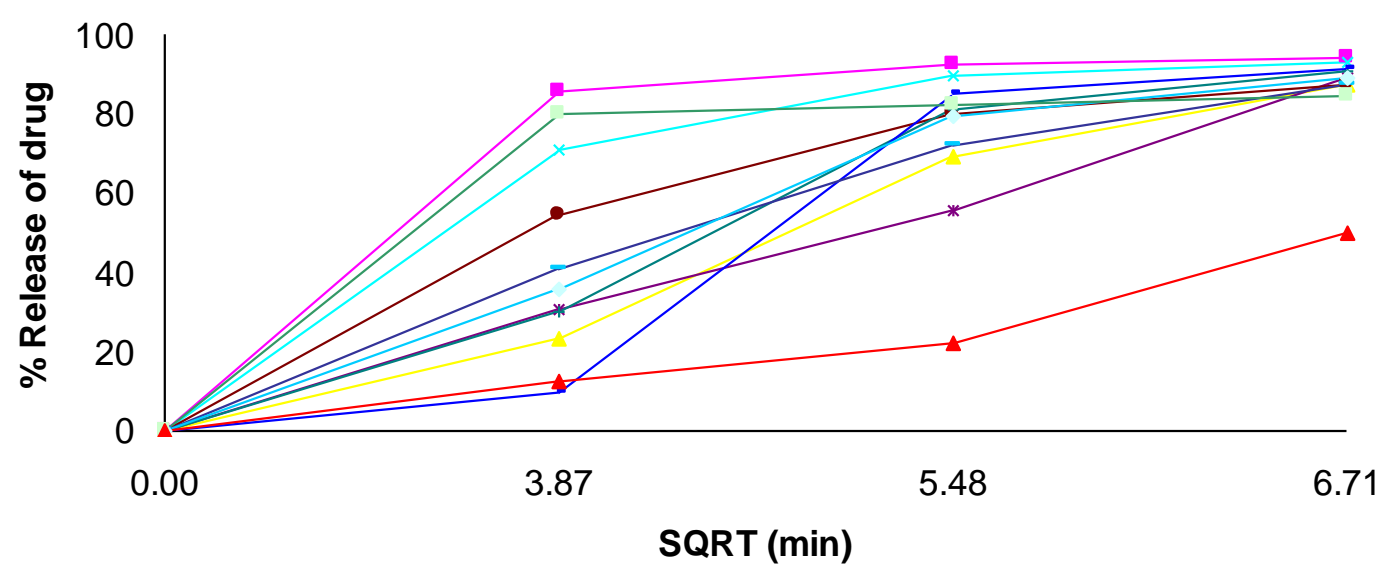

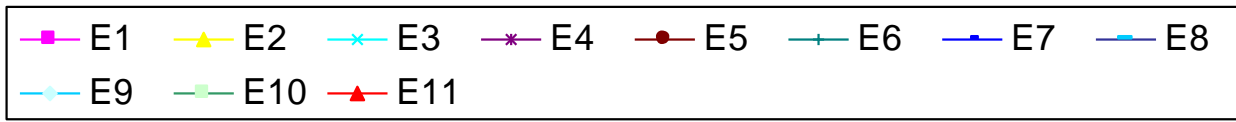

Figure 3. Higuchi plots of different brands of Esomeprazole. 


\section{RESULT AND DISCUSSION}

Commercially available ten national brands (E2, E3, E4, E5, E6, E7, E8, E9, E10 and E11) with originator brand (E1) of esomeprazole tablets were studied for their in vitro dissolution behavior in simulated gastric medium $(\mathrm{pH} 1.2)$ for 15 minutes time period and in simulated intestinal medium ( $\mathrm{pH}$ 6.8) for 30 minutes time period using USP reference dissolution apparatus to observe the release kinetics of the matrix tablets. Zero order release pattern is shown in Figure 1, first order in Figure 2 and Figure 3 represents the Higuchi release kinetics of the experimented brands.

Seven national (Except E2, E7 and E11) and originator brand complied with the USP in vitro dissolution specification, i.e., $25 \%$ drug release within 15 minutes in simulated gastric medium. After a comprehensive in vitro dissolution study, it was denoted that almost all national brands under investigation (E2, E3, E4, E5, E6, E7, E8 and E9) and originator brand (E1) fulfilled the USP in vitro dissolution specification (85\% drug release within 45 minutes) in simulated intestinal medium. Two of the national brands (E10, E11) failed to fulfill the USP in vitro dissolution specification i.e., $85 \%$ drug release within 45 minutes in simulated intestinal medium. This may be due to some formulation defects. The amount of drug present in each tablet was determined by spectroscopic method and except two; all the brands met the official standard.

The drug release mechanism was determined by multiple coefficients $\left(\mathrm{R}^{2}\right)$ and diffusion exponent (n) for each individual brands (Table 1). Zero order and Higuchi release kinetics was predominant release mechanism than first order release kinetics for three national brands (E2, E4 and E11). First order release kinetics was predominant for rest of the brands (E3, E5, E6, E7, E8, E9 and E10). It was found that drug release of those brands followed moderately diffusion method and was concentration dependant from the dosage form. Among all of these locally manufactured Esomeprazole brands E3, E6 and E7 showed compatible dissolution pattern and release kinetics compared with the reference brand.
Table 1. Multiple coefficients $\left(R^{2}\right)$ and diffusion exponent (n) values of different national brands with originator esomeprazole magnesium tablets available in Bangladesh Pharma market.

\begin{tabular}{ccccc}
\hline \multirow{2}{*}{ Code } & \multicolumn{3}{c}{$\begin{array}{c}\text { Multiple coefficient of } \\
\text { determination }\end{array} \mathbf{R}^{2}$ ) } & $\begin{array}{c}\text { Diffusion } \\
\text { exponent } \\
\text { (n) }\end{array}$ \\
\cline { 2 - 4 } & Zero order First order & Higuchi & 0.020 \\
E1 & 0.671 & 0.843 & 0.671 & 0.020 \\
E2 & 0.971 & 0.955 & 0.971 & 0.289 \\
E3 & 0.787 & 0.962 & 0.787 & 0.059 \\
E4 & 0.997 & 0.893 & 0.997 & 0.231 \\
E5 & 0.881 & 0.986 & 0.881 & 0.103 \\
E6 & 0.948 & 0.960 & 0.948 & 0.241 \\
E7 & 0.872 & 0.899 & 0.872 & 0.485 \\
E8 & 0.963 & 0.992 & 0.963 & 0.164 \\
E9 & 0.949 & 0.974 & 0.949 & 0.197 \\
E10 & 0.644 & 0.715 & 0.644 & 0.012 \\
E11 & 0.942 & 0.892 & 0.942 & 0.306 \\
\hline
\end{tabular}

\section{CONCLUSION}

This study revealed that most of the commercially available brands of Esomeprazole magnesium tablets in Bangladesh met the official specification and few of them failed which might have some formulation problems. The study also emphasized the need of constant surveillance on marketed drug product by the government, manufacturers and independent research groups to ensure supply and availability of quality medicines for the patients in Bangladesh.

\section{ACKNOWLEDGEMENT}

The authors would like to thank Beximco Pharmaceuticals Limited, Dhaka, Bangladesh for providing Standard Esomeprazole magnesium trihydrate and also Center for Excellence, University of Dhaka for technical support.

\section{REFERENCES}

Andersson T, Hassan-Alin M, Hasselgren G, et al. 2001. Pharmacokinetic studies with esomeprazole, the (S)-isomer of omeprazole. Clin Pharmacokinet. 40 (6): 411-26.

Augsburger LL, Shangraw RF, Giannini RP, Shah VP, Prasad VK, Brown D. 1983. Thiazides VIII: Dissolution Survey of marketed Hydrochlorothiazide tablets. J. Pharm. Sci. 72(8): 876-881. 
Aulton ME. 1988. Pharmaceutics: The Science of Dosage Form Design, 1st edition, LBS/Churchill Livingstone, Edinburgh. pp. 171.

Ayres JW, Huang H, Albert K. 1984. Effect of polymer in sustained release matrix tablet. J. Pharm. Sci. 73: 1629.

Fitton A, Wiseman L. 1996. Pantoprazole: a review of its pharmacological properties and clinical efficacy in the management of acid-related disorders. Drugs. 51 (3): 460-82.

Goodman and Gilman's 2001. The Pharmacological Basis of Therapeutics. 10th edition. McGraw-Hill Medical Publishing Division, pp.644-646.

Haider SS, Ahsan GM. 2001. Dissolution profiles of commercially available enteric coated tablets of non steroidal anti inflammatory drugs. J. Bangladesh Acad. Sci. 25(2): 149-155.

Longer MA, Robinson JR. 1990. Sustained Release Drug Delivery System, Martindale, 32nd Edition, the 'Complete Drug Reference' 2002. p.1225.

Remington's Pharmaceutical Science, Chapter 91, 18th edition, pp.1676-1690.

Sungthongjeen S, Pitaksuteepong T, Somsiri A, Sriamornsak P. 1999. Studies on pectins as potential hydrogel matrices for controlled-release drug delivery. Drug. Dev. Ind. Pharm. 25(12): 1271-1276.

United States Pharmacopeia XXIII and National Formulary XVII. 1995. United States Pharmacopeia Convention, Inc., Rand McNally, Taunton, p.1950.

Vakil N, Fennerty MB, 2003 Direct comparative trials of the efficacy of proton pump inhibitors in the management of gastro-oesophageal reflux disease and peptic ulcer disease Aliment Pharmacol Ther, 18 :559-68. 